\title{
Peripartum cardiomyopathy - a cardiovascular disease in pregnancy and puerperium. The actual state of knowledge, challenges, and perspectives
}

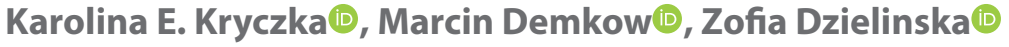 \\ Department of Coronary and Structural Heart Diseases, National Institute of Cardiology, Warsaw, Poland
}

\begin{abstract}
Peripartum cardiomyopathy (PPCM) is an idiopathic, multifactor cause of heart failure occurring at the end of pregnancy or in the first months after delivery. Although the prevalence of the disease is increasing, the awareness of both physicians and patients is rather low. Symptoms of PPCM are unspecific, making a prompt diagnosis even more difficult. In severe functional insufficiency and dilatation of the left ventricle, the recovery rate is particularly low. Therefore, the later PPCM is diagnosed, the more severe heart failure, and the worse the patient's outcome.

Despite the increasing frequency of PPCM, the exact pathophysiology and predictors of outcome are still not well determined. Therapeutic management in patients with PPCM remains a challenge, requiring a multidisciplinary approach.

At the base of the disease lies dysfunction of microcirculation with 16-kDa prolactin as the main trigger of this state. Therefore, adding bromocriptine to standard heart failure pharmacotherapy may be particularly beneficial.

In this review, we present the current state of knowledge and diagnostic and management recommendations and perspectives.
\end{abstract}

Key words: peripartum cardiomyopathy, pregnancy, bromocriptine

Ginekologia Polska 2021; 92, 2: 147-152

\section{INTRODUCTION}

In most European counties, including Poland, there is a lack of epidemiological data on the prevalence of cardiac diseases in pregnancy and associated complications. Data from Great Britain indicate that cardiac diseases, especially those unrecognised previously, are the leading cause of death in pregnant women [1].

Although it is rare, peripartum cardiomyopathy (PPCM) comprises a significant cause of heart failure in pregnancy and puerperium [2].

Approximately 50\% of patients with PPCM recover left ventricle's function. However, in the other $50 \%$ of young women at child-bearing age, the left ventricle (LV) impairment either persists or progresses to severe heart failure [2].

The aetiology of the disease is multifactorial and includes an inflammatory response to unbalanced oxidative stress, overproduction of inflammatory agents, and cathep$\sin D$ - an enzyme that induces proteolysis of full-length 23-kDa prolactin (PRL) with the generation of shorter 16-kDa fragment of PRL [3]. 16-kDa PRL induces endothelial and cardiomyocytic dysfunction, apoptosis, and it suppresses angiogenesis [3].

There is a lack of PPCM-specific treatments. However, bromocriptine - by suppressing PRL excretion from the pituitary gland - diminishes the substrate for $16-\mathrm{kDa}$ PRL formation [4].

Overall management of PPCM, especially in the acute heart failure stage, requires an intensive, multifactor approach [5].

\section{PPCM DEFINITION AND DIAGNOSIS}

PPCM is an idiopathic cardiomyopathy with a reduced left ventricular ejection fraction (LVEF) $<45 \%$ with or without LV enlargement, occurring in previously healthy women at the end of pregnancy or in first months after delivery $[1,2]$. No strict timeframes for the diagnosis of PPCM have been defined. However, PPCM onset is the most frequent in the first month postpartum (44\%) and at delivery (23\%). In pregnancy, PPCM was diagnosed in $6 \%$ of patients. The remaining $27 \%$ of women were diagnosed up to six months 
Table 1. Diagnosis of peripartum cardiomyopathy (PPCM)

\begin{tabular}{|c|c|c|}
\hline PPCM symptoms & Signs of left and right heart failure & Diseases to exclude \\
\hline $\begin{array}{l}\text { Fatigue } \\
\text { Decreased exercise tolerance } \\
\text { Dyspnoea } \\
\text { Cough } \\
\text { Orthopnoea } \\
\text { Palpitations } \\
\text { Chest pain } \\
\text { Peripheral oedema } \\
\text { Abdominal discomfort (congestion of the liver) }\end{array}$ & $\begin{array}{l}\text { Rales } \\
\text { Jugular venous distension } \\
\text { Gallop rhythm } \\
\text { Ascites } \\
\text { Peripheral oedema } \\
\text { Low blood pressure in cardiac decompensation } \\
\text { Peripartum hypercoagulation } \\
\text { Haemoptysis due to pulmonary embolism } \\
\text { Neurologic symptoms due to an acute } \\
\text { cerebrovascular event }\end{array}$ & $\begin{array}{l}\text { Heart failure exacerbation of previously } \\
\text { undiagnosed dilated cardiomyopathy } \\
\text { Pre-existing valve disease or congenital heart } \\
\text { disease } \\
\text { Myocarditis } \\
\text { Pulmonary embolism/ amniotic liquid } \\
\text { embolism } \\
\text { Myocardial infarction } \\
\text { Preeclampsia or sepsis }\end{array}$ \\
\hline
\end{tabular}

postpartum [6]. New onsets of PPCM thereafter are rare. However, primary mild, undiagnosed symptoms may aggravate after six months postpartum.

Awareness about the disease is rather low, and PPCM continues to be a late-recognised disease. It is especially important to diagnose PPCM at an early stage when chances for recovery are the highest [7]. Data shows that approximately $60 \%$ of PPCM patients seek a gynaecologist's advice before diagnosis by a cardiologist. Unfortunately, only $10 \%$ of these women are directly referred for cardiological consultation [7].

PPCM remains a challenge to diagnose because some signs and symptoms that occur during pregnancy and postpartum (e.g. exercise intolerance, leg oedema) may mask heart failure (Tab. 1). Moreover, there is no specific diagnostic test for PPCM. To confirm the diagnosis, other possible causes of heart failure must be excluded (Tab. 1) [8].

Therefore, it is essential to not leave women with peripartum dyspnoea without the diagnosis, as untreated PPCM may lead to further progression of heart failure and hemodynamic instability. To rule out or confirm the cardiac aetiology of dyspnoea, it is advisable to perform a simple examination and the following tests:

- 12-lead electrocardiography (ECG),

- B-type natriuretic peptide (BNP)/N-terminal pro-B-type natriuretic peptide (NT-proBNP) serum level,

- Echocardiography (Fig. 1) [2].

In case the patient is diagnosed with PPCM, strict follow-up is crucial. Even in women who present with mild symptoms, persisting LV insufficiency may be observed many months after delivery or may progress [9].

\section{PREVALENCE AND RISK FACTORS}

An accurate rate of the prevalence of PPCM worldwide has not yet been established. The highest prevalence was reported in Haiti at 1:299, and in South Africa at 1:1000. In Caucasians, the prevalence has increased in recent years from 1:1923 in 2004 to 1:1316 in 2011 [10, 11]. The latest EURObservational Research Registry on PPCM included 739 patients from 49 countries worldwide [12, 13]. Among them, 207 patients from 24 European countries constituted

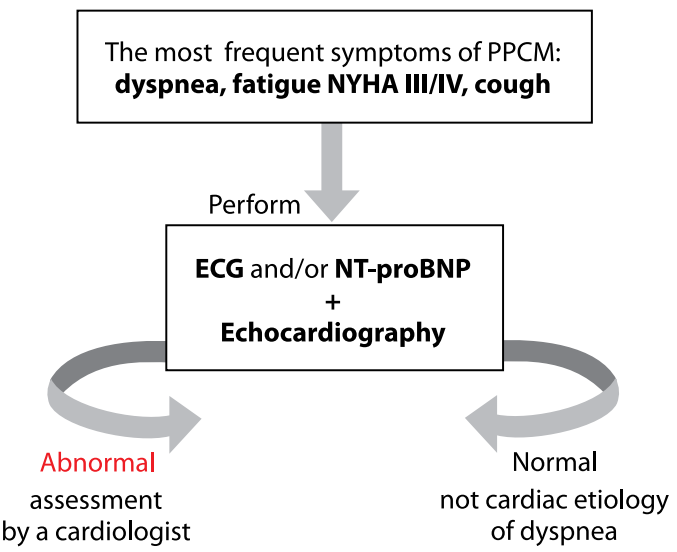

Figure 1. Diagnosis of peripartum cardiomyopathy (PPCM)

$27 \%$ of all women enrolled. There were also 16 women from Poland recruited, the majority of whom (nine patients) were enrolled in the National Institute of Cardiology in Warsaw. Poland was in fourth place, regarding the number of patients recruited, after Great Britain, Germany, and Macedonia. These data show that PPCM occurs globally, and it is a matter of awareness of the disease that influences the diagnosis rate.

Therefore, it is important to recognise the risk factors of PPCM, which include advanced or early maternal age ( $>30$ or $<18$ years, multiparity, twin pregnancies, hypertension, pre-eclampsia, prolonged use of beta-agonists, family history, a previous incidence of PPC, ethnicity, smoking $[2,14]$.

Observations made in the United States indicate that the mean age of women with PPCM has increased from 30.3 to 30.8 years. This data was found to be associated with a higher rate of comorbidities, such as hypertension, diabetes, dyslipidaemia, smoking, anaemia, obstructive pulmonary disease, hypothyroidism, chronic renal insufficiency, and atrial fibrillation [11].

\section{AETIOLOGY}

The aetiology of PPCM is not fully understood. In literature, there are plenty of possible pathophysiological mechanisms analysed. The main risk factors include inflammatory cytokines (INF-gamma, TNF-alpha, interleukin-6), apoptosis 


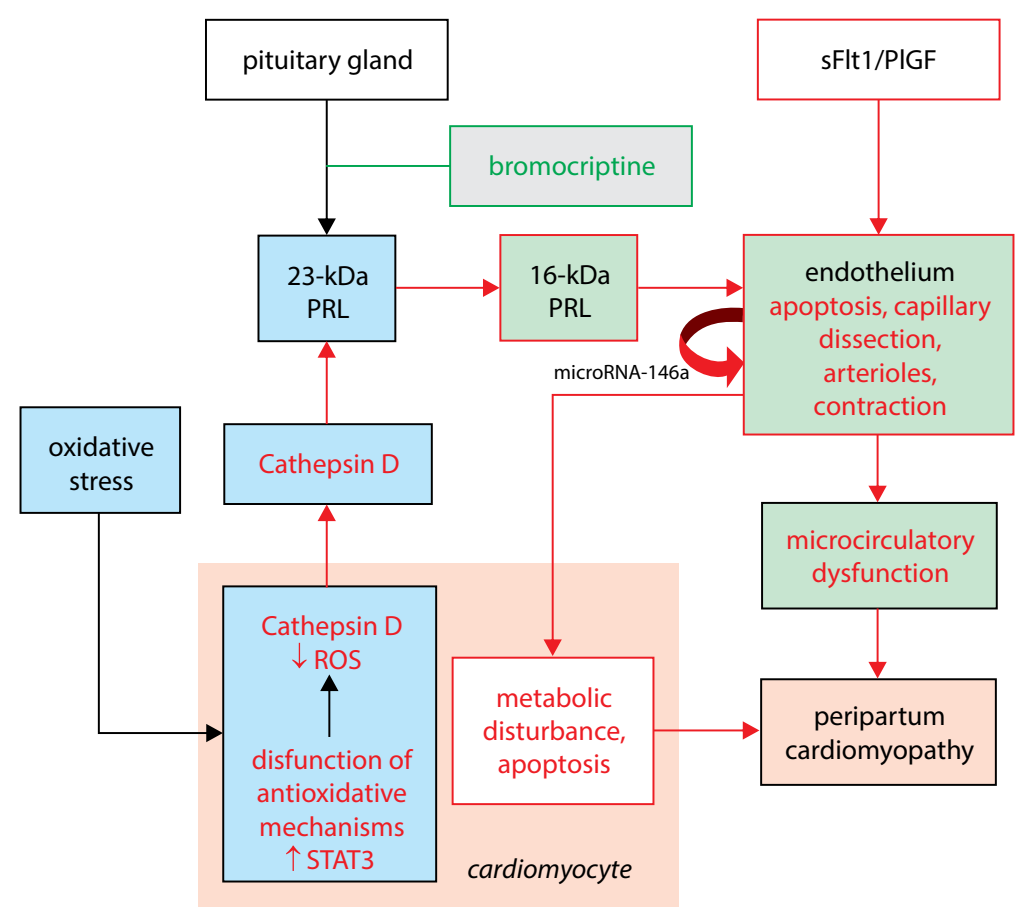

Figure 2. 16-kDa prolactin-dependent pathophysiological path in peripartum cardiomyopathy

(Fas/Apo-1), ox-LDL, and autoimmunological mechanisms including pregnancy-related autoimmunological disturbances (e.g. anti-actin antibodies), and the 16-kDa fragment of PRL [15-17].

Dysfunction of microvasculature and angiogenic imbalance seem to be the fundamental points that may be influenced by the vast majority of the pathophysiological risk factors of PPCM mentioned above. The dysfunction of microcirculation is directly resultant from endothelial dysfunction and the apoptosis of endothelial cells leading to the closure of capillary vessels by apoptotic bodies [18].

These changes, not present in dilated cardiomyopathy, are accompanied by the presence of preadipocytes, which may take part in neoangiogenesis by differentiating into endothelial cells [18]. Furthermore, an increased level of placental growth factor (PIGF) and a decreased level of soluble Fms-like tyrosine kinase (sFlt-1), resulting in a decreased sFIt-1/PIGF ratio, were found in PPCM patients after delivery [19]. These findings indicate the need for further exploration of the endothelial function in PPCM.

\section{6-KDA FRAGMENT OF PRL}

One of the main mechanisms proven to lead to endothelial dysfunction, and afterward to PPCM, is a depletion of signal transducers and activators of transcription-3 (STAT3), which protects against oxidative stress and apoptosis [3]. In the case of the depletion of STAT3, cathepsin D is activated. This enzyme cleaves a $16-k D a$ chain from the intact $23-k D a$ PRL. The shorter chain, via NF-kB path, increases synthesis of
microRNA-146a in endothelial cells. MicroRNA-146a inhibits migration, proliferation of endothelial cells, and angiogenesis. It also may trigger apoptosis leading to cardiomyocyte damage (Fig. 2) [3, 20].

\section{GENETIC PREDISPOSITION}

Cases of PPCM have also been described in families with a history of dilated cardiomyopathies [21]. These findings suggest a genetic predisposition to PPCM, with mutations in the titin gene being the most frequent [21]. Recently, we have reported that the interaction of biological factors such as a high PRL levels, ventricular arrhythmias, and autoimmune disorders could modify genetic predisposition. Additionally, we have noticed that a number of coexisting risk factors may also play a role [22].

\section{PROGNOSTIC FACTORS OF ADVERSE CARDIAC EVENTS IN PPCM}

PPCM presentation, response to treatment, and outcome may vary significantly between patients.

Although it is a potentially reversible cardiomyopathy, with about a $50 \%$ rate of recovery, LVEF impairment persists or progresses to a life-threatening condition in the second half of patients [2].

The mortality rate remains high and varies in different populations, from $1.36 \%$ (in-hospital mortality) to $30 \%$ in 47-month observation $[2,16]$.

The first six-month data from the EURObservational Research Registry on PPCM indicated that the total death rate 
was $6 \%$, and the reported rehospitalization rate was $10 \%$ [13]. The main reported causes of death were progressive heart failure, sudden deaths, arrhythmias (including VT and VF), and embolisation [12, 13].

Although the prevalence of PPCM is increasing, exact predictors of outcome are not well defined. Among them, the baseline LVEF $<30 \%$ and LV end-diastolic diameter $>60 \mathrm{~mm}$ was found to be associated with a low recovery and high mortality rate [14, 23]. Additional right ventricle impairment also worsens the patient's prognosis [2]. Moreover, patients with PPCM who had not improved their cardiac function by a six-month follow-up had higher baseline NT-proBNP levels [17].

Recent studies on CMRI revealed that early signs of fibrosis assessed by $\mathrm{T} 1$ and $\mathrm{T} 2$ mapping, especially increased extracellular volume $(E C V)$, are associated with a low rate of recoveries in long-term follow-up [24]. Also, elevated markers of fibrosis in PPCM were shown to be associated with poor LVEF recovery [25].

\section{PPCM MANAGEMENT}

According to data from the World Health Organisation, PPCM in pregnancy puts a patient at a significantly increased (19-27\%) or extremely high (> 40\%) risk of severe morbidity and mortality depending on LVEF (class III $30 \%-45 \%$ or IV LVEF < 30\%) [16]. This data indicates that a patient with PPCM should be managed at an expert centre for pregnancy and cardiac diseases. As PPCM is a complex phenomenon, multidisciplinary care including different specialists, such as cardiologists, obstetricians, and clinical geneticists, is obligatory for a satisfactory outcome $[5,16]$.

The treatment of PPCM should meet the heart failure guidelines and be adjusted if the patient is still pregnant, as in that period some medications are contraindicated $[5,26,27]$. Heart failure therapy in pregnancy mainly consists of diuretics, vasodilators (hydralazine, nitroglycerine), and beta-blockers [5, 27].

After delivery, treatment according to the BOARD (bromocriptine, oral heart failure therapy, anticoagulation, relaxants, and diuretics) concept is recommended [28].

According to the European Society of Cardiology's guidelines on heart diseases in pregnancy, bromocriptine should be considered (Class IIb) as an addition to beta-blockers and an angiotensin-converting enzyme inhibitor (ACE-I) or angiotensin receptor blocker (ARB) [16]. Different schemes of bromocriptine treatment have been proposed according to the severity of heart failure (Tab. 2).

Bromocriptine inhibits the release of PRL from the pituitary gland. This action leads to a decrease in the amount of substrate for 16-kDa PRL formation during imbalanced oxidative stress (Fig. 2).
One randomised trial on bromocriptine therapy with a control group has been conducted so far [4]. In this study, a significant benefit from the use of bromocriptine has been observed in a group of 20 women with PPCM [4]. The dosage of bromocriptine proposed in the study was $2.5 \mathrm{mg}$ twice daily for two weeks, followed by $2.5 \mathrm{mg}$ daily for four weeks.

Prolonged treatment with bromocriptine, up to eight weeks, was found to enhance LVEF recovery, especially in patients with severe LVEF impairment < 30\% [29].

It is worth noting that a placebo-controlled study on bromocriptine in PPCM is being conducted (ClinicalTrials. gov identifier: NCT02590601) [30].

The most beneficial bromocriptine treatment duration is yet to be established. However, such a prolonged treatment guided by serum PRL levels may be particularly beneficial [22]. Nevertheless, bromocriptine may evoke hypertension and increase hypercoagulation in the already increased hypercoagulative state associated with pregnancy and puerperium [2].

Recently, it was observed that plasminogen activator inhibitor-1 (PAI-1) is increased in patients with PPCM and plausibly possess a pathophysiological function in triggering endothelial dysfunction, cardiomyocyte injury, and myocardial fibrosis [31].

Treatment with low-molecular-weight heparin (LMWH) during bromocriptine administration is recommended after previous risk-benefit assessment [28, 29].

In the case of hemodynamic instability, treatment with inotropic agents should be introduced. As dopamine and dobutamine may increase heart failure associated with PPCM, levosimendan is the inotropic drug of choice, although its administration may be limited by hypotension [5].

As cardiac function can normalise within months in a significant number of PPCM patients, the decision to refer the patient for cardiac transplantation should not be made too early. A more recent study reports worse cardiac transplantation results, including higher rejection rates and higher mortality in women transplanted due to PPCM as compared to other patients [32].

Similarly, before any decision about the implantation of a cardioverter-defibrillator (ICD), individual clinical status (i.e. dyspnoea, history of syncope, arrhythmias) and other prognostic factors - not only LVEF — need to be evaluated. If available, a wearable cardioverter-defibrillator (WCD) should be considered in patients with LVEF under 35\% for six months [5, 11].

Key PPCM treatment issues are summarised in Table 2.

If treated efficiently, LVEF improvement is most often observed in the first 6-12 months after delivery [2,33]. However, some patients present late recoveries over 12 months [33]. The pharmacological treatment of heart failure may be gradually decreased after six months of maintaining 


\begin{tabular}{|c|c|}
\hline Antepartum & Postpartum \\
\hline $\begin{array}{l}\text { Drugs with foetal toxicity should be avoided } \\
\text { e.g. ACE-I, ARB, MRA }\end{array}$ & $\begin{array}{l}\text { Standard heart failure guidelines management BOARD: } \\
\text { bromocriptine + beta-blockers + ACE-I/ARB + LMWH + relaxants } \\
\text { (vasodilators) + diuretics } \\
\text { - MRA, Ivabradine, verapamil with sacubitril (Entresto) in a later stage, } \\
\text { if appropriate }\end{array}$ \\
\hline $\begin{array}{l}\text { Diuretics (furosemide) } \\
\text { Risk of hypovolemia, hypoperfusion of uterus and oligohydramnios } \\
\text { Vasodilators } \\
\text { Hydralazine, nitrates } \\
\text { - decreased vascular resistance } \\
\text { - increased cardiac output and stroke volume } \\
\text { - The risk of: } \\
\text { - tachycardia, headache } \\
\text { - angina (hydralazine) } \\
\text { - increased uterus contractility (hydralazine) }\end{array}$ & $\begin{array}{l}\text { Bromocriptine } \\
\text { May be considered to stop lactation and enhance LV recovery (IIb) [15]: } \\
\text { - in a patient with severe LV impairment LVEF }<25 \% \text { or in cardiogenic } \\
\text { shock: } \\
\text { - } 2 \times 2.5 \mathrm{mg} \text { for } 2 \text { weeks, then } 1 \times 2.5 \mathrm{mg} \text { for following } 4 \text { weeks } \\
\text { - } \text { in uncomplicated patients consider } 2.5 \mathrm{mg} \text { once daily for at least } \\
7 \text { days } \\
\text { - risk-benefit assessment (bromocriptine may increase } \\
\text { hypercoagulation and evoke hypertension) }\end{array}$ \\
\hline $\begin{array}{l}\text { Beta-blockers (except labetalol) } \\
\text { Risk of: } \\
\text { - lower foetal birth weight, IUGR, and bradycardia in a foetus } \\
\text { - hypertonia of the uterus } \\
\text { Monitoring of the foetus is necessary }\end{array}$ & $\begin{array}{l}\text { Statins } \\
\text { In case of hypercholesterolemia (except patients in acute heart failure } \\
\text { stage) }\end{array}$ \\
\hline
\end{tabular}

Severe PPCM course

NYHA class III/IV, HR $>130 / \mathrm{min}$ or $<45 / \mathrm{min}$

Saturation $<90 \%$, systolic blood pressure $<90 \mathrm{~mm} \mathrm{Hg}$

Lactates $>2 \mathrm{mmoL} / \mathrm{L}$, oliguria, cold skin, deteriorated mental state

Oxygenation, preload optimisation

hospitalisation in an intensive care unit

\begin{tabular}{|c|c|}
\hline Antepartum & Postpartum \\
\hline $\begin{array}{l}\text { Maturation of the foetus's lungs }>23 \mathrm{Hbd}+5 \text { days } \\
\text { (glucocorticosteroids } 24 \mathrm{~h} \text { before Caesarean section if possible) }\end{array}$ & $\begin{array}{l}\text { Bromocriptine } 2 \times 2.5 \mathrm{mg} \text { (up to } 10-20 \mathrm{mg} \text { daily, according to serum } \\
\text { prolactin levels, until normal values are reached) }\end{array}$ \\
\hline \multicolumn{2}{|c|}{$\begin{array}{l}\text { In the case of cardiogenic shock, consideration of levosimendan }(0.1 \mu \mathrm{g} / \mathrm{kg} / \mathrm{min} \text { for } 24 \mathrm{~h}) \text { instead of catecholamines. } \\
\text { Early transfer to an experienced centre } \\
\text { Early evaluation of mechanical circulatory support according to the centre's experience }\end{array}$} \\
\hline $\begin{array}{l}\text { 1. Optimised HF-therapy (as above) } \\
\text { 2. No response: digoxin, IABP/ECMO } \\
\text { 3. Caesarean section }\end{array}$ & $\begin{array}{l}\text { 1. Optimised HF-therapy (as above) } \\
\text { 2. No response: IABP/ECMO, LVAD, BiVAD (bridge to recovery or } \\
\text { transplant) }\end{array}$ \\
\hline
\end{tabular}

ACE-I — angiotensin-converting enzyme inhibitors; ARB — angiotensin receptors blockers, BiVAD — biventricular assist device; IABP — intraaortic balloon pump; ECMO - arterio-venous extracorporeal membrane oxygenation; ICD — implantable cardioverter-defibrillator; IUGR — intrauterine growth retardation; LMWH - lowmolecular-weight heparin; LVAD — left ventricle assist device; MRA — mineralocorticoids receptor antagonists; WCD — wearable cardioverter-defibrillator

LVEF > 50\%. However, drugs cannot be discontinued in all patients who have recovered.

It is important to remember that if LVEF does not increase above $50 \%$, the risk of heart failure relapse in the next pregnancy as high as $56 \%$ with a mortality rate of $12 \%$ [34]. On the other hand, in case of subsequent pregnancies of PPCM patients, prophylactic bromocriptine administration directly after delivery with standard HF therapy improved outcomes [34].

\section{Co-morbidities}

The patient with PPCM needs to have a strict ambulatory follow-up performed in case she develops other conditions such as postpartum thyroiditis - the most frequent autoimmune disorder after delivery that may also affect the course of PPCM $[22,35]$.

\section{SUMMARY}

PPCM remains a significant cause of heart failure in pregnancy and postpartum. Undiagnosed PPCM may rapidly progresses into a life-threatening condition. The primary diagnosis of pregnancy/puerperium-associated dyspnoea should include ECG, NT-proBNP, and echocardiography. Strict ambulatory monitoring during treatment is essential in case of the development of other cardiac and extracardiac conditions. It would be advisable to conduct a Polish PPCM 
Registry, as there is no data related to PPCM prevalence, course, or outcome available for the country. Moreover, such a registry may be the impetus for studies that may identify new pathophysiological pathways active in PPCM aetiology. These may lead to the discovery of new therapeutic agents that improve patients' survival.

\section{REFERENCES}

1. Roos-Hesselink JW, Duvekot JJ, Thorne SA. Pregnancy in high risk cardiac conditions. Heart. 2009; 95(8): 680-686, doi: 10.1136/hrt.2008.148932, indexed in Pubmed: 19329725.

2. Sliwa K, Hilfiker-Kleiner D, Petrie MC, et al. Heart Failure Association of the European Society of Cardiology Working Group on Peripartum Cardiomyopathy. Current state of knowledge on aetiology, diagnosis, management, and therapy of peripartum cardiomyopathy: a position statement from the Heart Failure Association of the European Society of Cardiology Working Group on peripartum cardiomyopathy. Eur J Heart Fail. 2010; 12(8): 767-778, doi: 10.1093/eurjhf/hfq120, indexed in Pubmed: 20675664.

3. Hilfiker-Kleiner D, Kaminski K, Podewski E, et al. A cathepsin D-cleaved $16 \mathrm{kDa}$ form of prolactin mediates postpartum cardiomyopathy. Cell. 2007; 128(3): 589-600, doi: 10.1016/j.cell.2006.12.036, indexed in Pubmed: 17289576.

4. Sliwa K, Blauwet L, Tibazarwa K, et al. Evaluation of bromocriptine in the treatment of acute severe peripartum cardiomyopathy: a proof-of-concept pilot study. Circulation. 2010; 121(13): 1465-1473, doi: 10.1161/CIRCULATIONAHA.109.901496, indexed in Pubmed: 20308616.

5. Bauersachs J, Arrigo M, Hilfiker-Kleiner D, et al. Current management of patients with severe acute peripartum cardiomyopathy: practical guidance from the Heart Failure Association of the European Society of Cardiology Study Group on peripartum cardiomyopathy. Eur J Heart Fail. 2016; 18(9): 1096-1105, doi: 10.1002/ejhf.586, indexed in Pubmed: 27338866.

6. Haghikia A, Podewski E, Libhaber E, et al. Phenotyping and outcome on contemporary management in a German cohort of patients with peripartum cardiomyopathy. Basic Res Cardiol. 2013; 108(4): 366, doi: 10.1007/s00395-013-0366-9, indexed in Pubmed: 23812247.

7. Kamiya CA, Kitakaze $M$, Ishibashi-Ueda $H$, et al. Different characteristics of peripartum cardiomyopathy between patients complicated with and without hypertensive disorders. -Results from the Japanese Nationwide survey of peripartum cardiomyopathy-. Circ J. 2011; 75(8): 1975-1981, doi: 10.1253/circj.cj-10-1214, indexed in Pubmed: 21617320.

8. Kryczka K, Dzielińska Z, Przybylski A, et al. Therapeutic challenges and management of heart failure during pregnancy (partl). Med Sci Monit. 2012; 18(5):CQ5-CQ7, doi: 10.12659/msm.882716, indexed in Pubmed: 22534703.

9. Hilfiker-Kleiner D, Haghikia A, Nonhoff J, et al. Peripartum cardiomyopathy: current management and future perspectives. Eur Heart J. 2015; 36(18): 1090-1097, doi: 10.1093/eurheartj/ehv009, indexed in Pubmed: 25636745.

10. Mielniczuk LM, Williams K, Davis DR, et al. Frequency of peripartum cardiomyopathy. Am J Cardiol. 2006; 97(12): 1765-1768, doi: 10.1016/j. amjcard.2006.01.039, indexed in Pubmed: 16765131.

11. Elkayam U. Clinical characteristics of peripartum cardiomyopathy in the United States: diagnosis, prognosis, and management. J Am Coll Cardiol. 2011; 58(7): 659-670, doi: 10.1016/j.jacc.2011.03.047, indexed in Pubmed: 21816300.

12. Sliwa K, Mebazaa A, Hilfiker-Kleiner D, et al. Clinical characteristics of patients from the worldwide registry on peripartum cardiomyopathy (PPCM): EURObservational Research Programme in conjunction with the Heart Failure Association of the European Society of Cardiology Study Group on PPCM. Eur J Heart Fail. 2017; 19(9): 1131-1141, doi: 10.1002/ejhf.780, indexed in Pubmed: 28271625.

13. Sliwa $K$, Petrie $M C$, van der Meer $P$, et al. Clinical presentation, management, and 6-month outcomes in women with peripartum cardiomyopathy: an ESC EORP registry. Eur Heart J. 2020 Aug 25; ehaa455. doi:10.1093/eurheartj/ehaa455.

14. Fett JD, Markham DW. Discoveries in peripartum cardiomyopathy. Trends Cardiovasc Med. 2015; 25(5): 401-406, doi: 10.1016/j.tcm.2014.10.019, indexed in Pubmed: 25557957.

15. Sliwa K, Förster O, Libhaber E, et al. Peripartum cardiomyopathy: inflammatory markers as predictors of outcome in 100 prospectively studied patients. Eur Heart J. 2006; 27(4): 441-446, doi: 10.1093/eurheartj/ehi481, indexed in Pubmed: 16143707.

16. Regitz-Zagrosek V, Roos-Hesselink JW, Bauersachs J, et al. ESC Scientific Document Group. 2018 ESC Guidelines for the management of cardio- vascular diseases during pregnancy. Eur Heart J. 2018; 39(34): 31653241, doi: 10.1093/eurheartj/ehy340, indexed in Pubmed: 30165544.

17. Forster $\mathrm{O}$, Hilfiker-Kleiner $\mathrm{D}$, Ansari $\mathrm{AA}$, et al. Reversal of IFN-gamma, oxLDL and prolactin serum levels correlate with clinical improvement in patients with peripartum cardiomyopathy. Eur J Heart Fail. 2008; 10(9): 861-868, doi: 10.1016/j.ejheart.2008.07.005, indexed in Pubmed: 18768352.

18. Fidziańska A, Walczak E, Glinka Z, et al. Ultrastructural evidence of myocardial capillary remodeling in peripartum cardiomyopathy. Med Sci Monit. 2010; 16 (5): CS62-66. https://www.medscimonit.com/download/index/idArt/878530.

19. Mebazaa A, Seronde MF, Gayat E, et al. Imbalanced angiogenesis in peripartum cardiomyopathy - diagnostic value of placenta growth factor. Circ J. 2017; 81(11): 1654-1661, doi: 10.1253/circj.CJ-16-1193, indexed in Pubmed: 28552862.

20. Halkein J, Tabruyn SP, Ricke-Hoch M, et al. MicroRNA-146a is a therapeutic target and biomarker for peripartum cardiomyopathy. J Clin Invest. 2013; 123(5): 2143-2154, doi: 10.1172/JCl64365, indexed in Pubmed: 23619365.

21. van Spaendonck-Zwarts KY, Posafalvi $A$, van den Berg MP, et al. Titin gene mutations are common in families with both peripartum cardiomyopathy and dilated cardiomyopathy. Eur Heart J. 2014; 35(32): 2165-2173, doi: 10.1093/eurheartj/ehu050, indexed in Pubmed: 24558114.

22. Kryczka KE, Dzielińska Z, Franaszczyk M, et al. Severe course of peripartum cardiomyopathy and subsequent recovery in a patient with a nove TTN gene-truncating mutation. Am J Case Rep. 2018; 19: 820-824, doi: 10.12659/AJCR.909601, indexed in Pubmed: 29997384.

23. McNamara DM, Elkayam U, Alharethi R, et al. IPAC Investigators. Clinical outcomes for peripartum cardiomyopathy in North America: Results of the IPAC Study (Investigations of Pregnancy-Associated Cardiomyopathy). J Am Coll Cardiol. 2015; 66(8): 905-914, doi: 10.1016/j. jacc.2015.06.1309, indexed in Pubmed: 26293760.

24. Liang YD, Xu YW, Li WH, et al. Left ventricular function recovery in peripartum cardiomyopathy: a cardiovascular magnetic resonance study by myocardial T1 and T2 mapping. J Cardiovasc Magn Reson. 2020; 22(1): 2, doi: 10.1186/s12968-019-0590-z, indexed in Pubmed: 31902370.

25. Azibani F, PfefferTJ, Ricke-Hoch M, et al. Outcome in German and South African peripartum cardiomyopathy cohorts associates with medical therapy and fibrosis markers. ESC Heart Fail. 2020; 7(2): 512-522, doi: 10.1002/ehf2.12553, indexed in Pubmed: 32064780.

26. Ponikowski P, Voors AA, Anker SD, et al. ESC Scientific Document Group. 2016 ESC Guidelines for the diagnosis and treatment of acute and chronic heart failure: The Task Force for the diagnosis and treatment of acute and chronic heart failure of the European Society of Cardiology (ESC) Developed with the special contribution of the Heart Failure Association (HFA) of the ESC. Eur Heart J. 2016; 37(27): 2129-2200, doi: 10.1093/eurheartj/ehw128, indexed in Pubmed: 27206819.

27. Azibani F, Sliwa K. Peripartum cardiomyopathy: an update. Curr Heart Fail Rep. 2018; 15(5): 297-306, doi: 10.1007/s11897-018-0404-x, indexed in Pubmed: 30051292

28. Arrigo M, Blet A, Mebazaa A. Bromocriptine for the treatment of peripartum cardiomyopathy: welcome on BOARD. Eur Heart J. 2017; 38(35): 26802682, doi: 10.1093/eurheartj/ehx428, indexed in Pubmed: 28934838.

29. Hilfiker-Kleiner D, Haghikia A, Berliner D, et al. Bromocriptine for the treatment of peripartum cardiomyopathy: a multicentre randomized study. Eur Heart J. 2017; 38(35): 2671-2679, doi: 10.1093/eurheartj/ehx355, indexed in Pubmed: 28934837.

30. https://clinicaltrials.gov/ct2/show/study/NCT02590601

31. Ricke-Hoch M, Hoes MF, Pfeffer TJ, et al. In peripartum cardiomyopathy plasminogen activator inhibitor-1 is a potential new biomarker with controversial roles. Cardiovasc Res. 2020; 116(11): 1875-1886, doi: 10.1093/cvr/cvz300, indexed in Pubmed: 31711127.

32. Rasmusson K, Brunisholz K, Budge D, et al. Peripartum cardiomyopathy: post-transplant outcomes from the United Network for Organ Sharing Database. J Heart Lung Transplant. 2012; 31(2): 180-186, doi: 10.1016/j. healun.2011.11.018, indexed in Pubmed: 22305380.

33. Biteker $M$, Ilhan $E$, Biteker $G$, et al. Delayed recovery in peripartum cardiomyopathy: an indication for long-term follow-up and sustained therapy. Eur J Heart Fail. 2012; 14(8): 895-901, doi: 10.1093/eurjhf/hfs070, indexed in Pubmed: 22588321.

34. Hilfiker-Kleiner D, Haghikia A, Masuko D, et al. Phenotyping and outcome on contemporary management in a German cohort of patients with peripartum cardiomyopathy. Basic Res Cardiol. 2013; 108(4): 366-1728, doi: 10.1007/s00395-013-0366-9, indexed in Pubmed: 23812247.

35. Groer M, Jevitt $C$. Symptoms and signs associated with postpartum thyroiditis. JThyroid Res. 2014; 2014: 531969, doi: 10.1155/2014/531969, indexed in Pubmed: 25405057. 